\title{
A PAISAGEM NA ANÁLISE GEOGRÁFICA: CONSIDERAÇÕES SOBRE UMA PAISAGEM RURAL EM GUARAPUAVA - PR
}

\author{
FERNANDO VERONEZZI ${ }^{1}$ \\ Universidade Estadual de Maringá \\ SERGIO FAJARDO ${ }^{2}$ \\ Universidade Estadual do Centro-Oeste
}

Resumo: O presente artigo aborda a paisagem como uma categoria de análise importante para a Geografia, apresentando o conceito a partir da ótica Humana da disciplina. Assim, por meio da percepção dos moradores da área próxima ao rio Guabiroba, em Guarapuava - PR, procurou-se interpretar a relação dos proprietários com a paisagem do seu entorno. Nessa direção, a relação destes com a paisagem rural envolve questões das esferas econômica, social, cultural e ambiental - entre as quais se destaca a prática da agricultura orgânica como tendência e elemento fundamental para a leitura da paisagem rural em questão.

Palavras-chave: Paisagem; Paisagem Rural; Categorias Geográficas; Agricultura Orgânica.

\section{LANDSCAPE IN GEOGRAPHICAL ANALYSIS: CONSIDERATIONS ABOUT A RURAL LANDSCAPE IN GUARAPUAVA (PARANÁ STATE, BRAZIL) \\ Abstract: This paper discusses the landscape as an important category of analysis for Geography,}

\footnotetext{
${ }^{1}$ Licenciado em Geografia pela Universidade Estadual do Centro-Oeste, mestrando no Programa de Pós-Graduação em Geografia (PGE) da Universidade Estadual de Maringá e bolsista Capes. Contato: fernandoveronezzi117@hotmail.com.

${ }^{2}$ Professor do Departamento de Geografia e do Programa de Pós-Graduação em Geografia da Universidade Estadual do Centro-Oeste (PR), em Guarapuava - PR; doutor em Geografia pela UNESP (2007) e mestre em Geografia pela Universidade Estadual de Maringá (2000), onde também se graduou em Geografia (1997). Contato: sergiofajardo@ hotmail.com.
} 
presenting the concept from the social perspective. Through of the perception of the residents of the area near the river Guabiroba in Guarapuava, Paraná State, we tried to interpret the relationship of the owners with the surrounding landscape. In this sense, their relationship with the rural landscape involves issues of economic, social, cultural and environmental spheres, among which stands out the practice of organic agriculture as a trend and as an essential element for analyzing the rural landscape in question.

Keywords: Landscape; Rural Landscape; Geographical Categories; Organic Agriculture.

\section{Introdução}

Este trabalho é o resultado de questionamentos efetuados durante a execução de um projeto de pesquisa na área de Geografia Agrária, na paisagem da Bacia Hidrográfica do Rio Guabiroba, zona rural de Guarapuava, região centro-sul do Estado do Paraná. Por meio do desenvolvimento de pesquisas de campo e da análise de entrevistas realizadas com pequenos proprietários locais, se identificou algumas situações que potencializaram a reflexão sobre a temática abordada nesse texto

Seguindo esse raciocínio, trabalhar questões que envolvem as paisagens rurais é essencial para compreendermos tanto a dinâmica econômica, quanto a dos indivíduos que nelas estão inseridos, além de promover um resgate aos estudos teóricos e conceituais que envolvem o termo paisagem na Geografia. Assim, esse estudo é relevante, pois pesquisas voltadas ao entendimento das atividades agropecuárias são de importância considerável para a compreensão dos processos/elementos/sujeitos que (re)criam as paisagens rurais conforme determinadas motivações. Nesse sentido, a prática da agricultura orgânica como processo produtivo é evidenciada e explicada neste ensaio.

Para o desenvolvimento metodológico da pesquisa foram essenciais as saídas a campo, a execução de entrevistas com pequenos produtores, a organização dos relatos das experiências vividas através de um diário de campo, além da produção de imagens fotográficas. Esses elementos serviram como base para posterior análise da realidade da paisagem da Bacia Hidrográfica do Rio Guabiroba (denominada a partir de agora de "paisagem rural do Guabiroba"), localizada em Guarapuava - PR.

Cabe ressaltar que as possibilidades de interpretação e sistematização do conhecimento são múltiplas e, aqui, a utilização do conceito de paisagem tem como finalidade reacender o debate teórico acerca de uma categoria de análise importante para a ciência geográfica, bem como observar e entender a realidade de uma paisagem rural específica. 


\section{Considerações acerca da Paisagem como categoria analítica da Geografia}

Com base em análises literárias sobre a temática em questão, até meados do século XVIII a paisagem era apenas observada nas pinturas bucólicas de artistas da época. Foi com esta relação entre arte e lugar que os estudos de paisagem foram se desenvolvendo (SALGUEIRO, 2001) e, atualmente, ela é uma das categorias de análise mais importantes da Geografia.

Dessa forma, Christofoletti (1999) contribui para o entendimento de tal conceito quando sugere que a utilização do termo paisagem está ligada ao vocábulo italiano paesaggio, introduzido com a finalidade de representar a natureza através das pinturas no período da Renascença. Cosgrove (2004, p. 98), em relação à utilização da paisagem nesse período, destaca que "a palavra surgiu (...) para indicar uma nova relação entre o ser humano e seu ambiente". O autor, ainda se referindo a esse período da história, revela que

(...) esta também foi a época quando o espaço terrestre estava sendo mapeado racionalmente nas quadrículas de sofisticadas projeções de mapas, enquanto paisagens humanas (...) estavam sendo construídas nas capitais como Roma, São Petersburgo e (...) sobre a vastidão dos territórios coloniais além-mar (COSGROVE, 2004,p. 99).

Assim, a paisagem é um conceito-chave, ou seja, um conceito capaz de fornecer unidade e identidade à Geografia num contexto de afirmação da disciplina (CORRÊA; ROSENDAHL, 2004). Refletir e promover um debate teóricoconceitual da paisagem se torna colaboração indispensável ao seu desenvolvimento, bem como significa avançar no âmbito epistemológico da ciência geográfica.

Os estudos conceituais na Geografia são valorosos e vêm sendo cada vez mais abordados por vários autores em diversos eventos e periódicos científicos (MENDONÇA, 2001). Ainda para Mendonça (2001), cada uma das ciências busca elementos e fundamentos que proporcionam a "comprovação de suas verdades", o que permite um desenvolvimento na maneira de se pensar e de fazer ciência.

Bruni e Andrade (s.d, p. 9) destacam que conceitos "são as idéias mais elementares" que um estudo ou uma ciência pode oferecer e, por isso, se apresentará aqui uma breve discussão teórica acerca da trajetória e da importância do conceito de paisagem na ciência geográfica. Na Geografia, conforme exemplifica Lisboa (2007, p. 25), existem diversos conceitos que também são chamados de categorias de análise. Nesta ciência a paisagem, o espaço, o tempo, a região, o território, as territorialidades, as redes e escalas geográficas são os mais elementares. Eles, como mencionado anteriormente, são importantes para os 
estudos geográficos e foram se desenvolvendo e se atualizando ao longo da história da ciência e conforme a necessidade de se compreender a complexidade do mundo. Para a Geografia o conceito de paisagem é significativo pois dá a ela um caráter diferencial em relação a outras ciências que também estudam e descrevem a superfície da Terra (CAPEL, 1981).

Em relação à trajetória do conceito, Maximiliano (2004, p.87) destaca que "tanto a escola alemã, como a francesa, que influenciaram a Geografia brasileira, dão ênfase a aspectos diferentes da paisagem. A Geografia alemã tem herança naturalista, desde Humboldt; a francesa desenvolveu observações quanto à região, formada pelas culturas e sociedades em cada espaço natural".

No que se refere à abordagem de paisagem na Geografia, Corrêa e Rosendahl (2004, p. 7) sugerem que o referido conceito tem variado ao longo da evolução da epistemologia da Geografia; e Schier (2003), ainda propõe que desde muito tempo o conceito de paisagem vem sendo abordado e discutido para que se possa chegar a uma determinada relação entre suas características naturais e sociais em um determinado espaço.

E assim, como afirma Passos (1998, p. 87), o termo paisagem “(...) ocupou e ocupa um lugar todo particular no campo da Geografia". Risso $(2008$, p. 68) faz algumas considerações acerca de como o conceito foi se desenvolvendo ao longo dos estudos geográficos:

(...) a noção de paisagem na Geografia nasceu sobre a observação de áreas visualmente homogêneas. Dentro da Geografia alemã (XVIII), até os anos de 1940, a paisagem englobava o conjunto de fatores naturais e humanos. Durante o século XIX, três estudiosos alemães se destacaram: Humboldt, Ritter e Ratzel. Sob o olhar do naturalista Humboldt, a paisagem era vista de forma holística, associada a um conjunto de fatores naturais e humanos.

É a partir desse contexto que Mendonça (2001) revela que a origem da concepção de paisagem que há hoje está intimamente relacionada aos geógrafos alemães do século XIX. Segundo ele esse conceito surge por meio de observações científicas desenvolvidas pelos europeus no início do daquele século, através de suas viagens. A construção desta categoria de análise se desenvolveu devido aos grandes naturalistas daquele período histórico.

Pelo fato de ser concebida tendo por bases as descrições dos aspectos físicos da superfície da Terra, alguns geógrafos do inicio do século XX - inquietos com a dicotomia que poderia surgir a partir das análises das pesquisas que levavam em consideração a paisagem - afirmavam que ela deveria ser entendida como um conceito integrador entre os aspectos físicos e humanos, pois, assim, permitiria e apresentaria a partir de sua análise interpretativa as significações e inter-relações 
dos elementos sociais e físicos em uma determinada área (SALGUEIRO, 2001). Mendonça (2001, p. 46) propõe que, para compreender o termo, é necessário considerar uma lógica geral da língua portuguesa na qual se tem um "espaço de terreno que se abrange num lance de vista [e] é tudo aquilo que é perceptível aos olhos, compreendendo, um conjunto de elementos em dada porção do planeta".

Schier (2003) argumenta que os estudos da paisagem por meio da ótica humana vêm se desenvolvendo desde 1890, com o geógrafo alemão Otto Schüter. Este autor redige no ano de 1907 uma breve teoria pela qual revela a paisagem como um dos objetos de estudo que compõem a Geografia Humana. A partir dos escritos de Otto várias outras observações e considerações foram sendo propostas pelos pesquisadores que estudaram e estudam a paisagem na Geografia.

Nos trabalhos conceituais de paisagem, Fajardo (2005, p 32) indica que há uma "imprecisão na diversidade conceitual" deste termo pois ele é polissêmico e, portanto, se deve analisá-lo de forma minuciosa a fim de que não se cometam equívocos. Tal conceito possui um caráter dinâmico, mesmo que muitos pesquisadores ainda o analisem "superficialmente, limitando-se aos aspectos visíveis do real" (FAJARDO, 2008, p. 47).

Em relação à sua gênese, Salgueiro (2001) indica que esta categoria de análise foi se desenvolvendo de uma forma mais ligada à Geografia Física, buscando, com o passar do tempo, colocar em seu entendimento preocupações de cunho econômico e cultural. Porém, a autora portuguesa revela - baseada nos estudos de Bertand e Dollfus (1973) - que os pesquisadores, na maioria das vezes, desenvolvem seus trabalhos com base nas condições "biogeográficas" da paisagem, muito distantes ainda das preocupações quanto ao econômico e ao social. Desta forma, "a paisagem é uma marca, pois expressa uma civilização, (...) que canaliza, em certo sentido, a relação de uma sociedade com o espaço e com a natureza (BERQUE, 1998, p. 84-85).

Bertrand (2004), em seus estudos, já alertava ao dizer que não existem apenas as paisagens naturais. As paisagens totais também são um fato real, ou seja, uma paisagem total é aquela que integra todos os elementos das ações humanas e naturais.

Levando-se em consideração a perspectiva humana do conceito, evidenciam-se os estudos do geógrafo francês Georges Bertrand, no qual o autor afirma que,

(...) a paisagem não é a simples adição de elementos geográficos disparatados. É uma determinada porção do espaço, resultado da combinação dinâmica, portanto instável, de elementos físicos, biológicos e antrópicos que, reagindo dialeticamente uns sobre os outros, fazem da paisagem um conjunto único e indissociável, em perpétua evolução (BERTRAND, 2004, p. 141). 
Milton Santos (1997), por sua vez, apresenta seu ponto de vista acerca das inúmeras possibilidades de interpretação do termo e evidencia a amplitude que o conceito apresenta ao afirmar que a paisagem pode ser considerada como

(...) tudo aquilo que nós vemos, o que nossa visão alcança, é a paisagem. Esta pode ser definida como o domínio do visível, aquilo que a vista abarca. Não é formada apenas de volumes, mas também de cores, movimentos, odores, sons etc. (SANTOS, 1997, p. 61).

Mais uma vez, o pensamento de Milton Santos contribui para o desenvolvimento teórico e conceitual quando o autor esclarece que "a paisagem é um conjunto de formas que, num dado momento, exprime as heranças que representam as sucessivas relações localizadas entre homem e natureza (...)" (SANTOS, 2002, p. 103). Donde se destaca a relação existente entre os aspectos naturais e sociais inseridos na paisagem, que deve ser levada em consideração quando analisada.

Resulta disso que a "paisagem (...) se constitui como uma realidade atual construída através do acúmulo de acontecimentos ou eventos passados, uma vez que o que é observado em uma paisagem da atualidade passou por um processo de constantes mudanças" (LISBOA, 2007, p.27).

$\mathrm{Na}$ concepção humana um elemento essencial para a interpretação desse conceito é a subjetividade. Enquanto na concepção física do termo pode-se "considerar a paisagem como uma parte da superfície da Terra", na perspectiva humana deve-se somar a essa afirmação a "ideia de a paisagem ser um território visto e sentido, cada vez mais subjetivo e elaborado pela mente" (SALGUEIRO, 2001, p. 37).

A subjetividade do pesquisador na compreensão da paisagem se apresenta como um dos motivos para que se leve em consideração as experiências e percepções de diversas culturas ao se tratar tal conceito no âmbito da Geografia Humana. Dessa maneira, considera-se que a categoria de análise é abrangente, devendo-se, assim, analisar as ações dos diversos agentes inseridos no processo de construção da paisagem, independente do propósito colocado sobre a leitura da paisagem.

Também nesse sentido, Passos (1998, p. 88) argumenta sobre a questão e revela que "(...) o olhar colocado sobre as paisagens é às vezes subjetivo e plural. A realidade paisagística é percebida por observadores de um lugar, de um tempo, de uma cultura e ela é objeto de uma apresentação que é representação".

A partir dessas proposições, Salgueiro (2001, p. 44) afirma que os "geógrafos humanos e os que estão ligados às escolas do comportamento e do espaço vivido" são os que se preocupam com a paisagem de uma forma mais subjetiva, levando em consideração a sua construção a partir de um fator mental, adquirindo 
elementos ligados aos fatos vivenciados no território. A autora indica que, sobre este aspecto, se deve levar em consideração fatores empíricos e fatos do cotidiano para que se possa interpretar a paisagem com base nas concepções humanísticas.

Sobre o aspecto subjetivo que concerne ao conceito de paisagem se deve levar em consideração os seguintes elementos propostos por Risso (2008, p. 72-73):

(...) no universo subjetivo estão incluídos os sentimentos em relação às paisagens, ou seja, afetividades, vivências, experiências, valores, a cultura simbólica, as representações, identidades e territorialidades, que, segundo o tipo de experiência com a Natureza, ou percepção, reflete diferentes sentimentos e comportamentos em relação a ela. Para cada pessoa ou grupo a paisagem terá um significado, porque as pessoas atribuem valores e significados diferentes às suas paisagens, traduzidos em sentimentos de enraizamento ou desapego aos lugares.

Nesse sentido, Risso (2008, p. 72) ainda sugere que, "as paisagens estão marcadas pelo universo subjetivo criado pelos seres humanos" e, desse modo, assim como argumenta Fajardo (2008, p. 59), "a paisagem consiste, sim, num olhar privilegiado do espaço, uma perspectiva de análise geográfica" e varia conforme as significações impressas pelos sujeitos a partir de suas atividades. Apresenta-se, a seguir, uma abordagem teórico-conceitual a partir de uma ramificação da paisagem: a paisagem rural.

\section{Compreendendo o conceito de Paisagem Rural}

Seguindo as ideias apresentadas anteriormente, Ribas Vilas (1992) sugere que a paisagem rural pode ser considerada a partir de uma marca essencial: a das ações antrópicas. Ou seja, pode ser entendida como resultado da ação de diversos fatores/sujeitos que se desenvolveram em tempos diferentes e que proporcionam características específicas à paisagem rural.

Dessa maneira, salienta-se que cabe ao geógrafo analisar a paisagem de forma que contemple o dinamismo existente nas relações entre sociedade-natureza, pois, desta forma, tem-se uma compreensão mais coerente da realidade. Milton Santos (1997, p. 65) intervém no debate e coloca que a paisagem deve ser analisada de maneira variada, pois ela é "um conjunto heterogêneo de formas naturais e artificiais".

Com base nessa conceituação, evidenciam-se algumas revelações acerca da temática que envolve a paisagem rural, na qual, com a evolução do pensamento geográfico, vão surgindo diversas formas de conceber o conceito. Em relação às 
paisagens rurais, Ribas Vilas (1992, p. 249) propõe que:

El paisaje rural es, portanto, donde más se evidencian las influencias de los tres grupos de elementos (abióticos, bióticos y antrópicos), y en el que pueden presentar un grado de jerarquía similar. Caso distinto del paisaje natural, donde dominan elementos abióticos y bióticos, y del urbano, donde domina los elementos antrópicos (RIBAS VILAS, 1992, p. 250).

Colaborando com tal reflexão, Fajardo (2008, p. 60) argumenta que,

(...) o campo enquanto espaço agrário ou meio rural oferece uma multiplicidade de leituras e interpretações. A paisagem rural constitui uma das abordagens que consegue captar os dois lados da moeda: a exploração da terra enquanto recurso econômico e, do outro lado, os recursos naturais impactados pelas atividades humanas.

A paisagem rural é complexa e deve ser analisada a partir dos diversos elementos que a compõem, não levando em consideração apenas a "aparência" (FAJARDO, 2008, p. 59). Além dos interesses econômicos, ela também apresenta inúmeros fatores socioculturais que devem ser levados em consideração numa análise interpretativa.

Contribuindo ainda para essa discussão, Ribas Vilas (1992) destaca que a diversidade da paisagem rural se apresenta com base nas diferentes formas de uso e exploração de cada cultura, bem como nas características físicas dessa paisagem. Tem-se, portanto, diversas formas que dependem da morfologia do terreno, dos tipos de solo, do clima local, além do tipo de utilização da propriedade, das técnicas empregadas e da organização das atividades praticadas.

Desse modo, Cavaco (2005, p. 78-79) conclui que a paisagem rural é "resultado do encontro entre o meio natural, a densidade agrícola, o tipo de sociedade, o povoamento, a morfologia agrária, os sistemas de cultura e de criação de gado e as técnicas de cultivo". A autora destaca ainda que a paisagem rural sempre é muito variável pois possui uma dinâmica que está em constante movimento e que a diversidade está intimamente ligada a esse tipo de paisagem.

As atividades socioeconômicas são elementos crucias e permitem entender os processos que produzem as paisagens rurais. Fajardo (2008, p. 48) mostra que as dinâmicas econômicas "modificam as paisagens (criando e recriando)", produzindo novas configurações. Nesse sentido, apresenta-se o conceito como uma das possibilidades de análise da realidade local (Guabiroba), pela qual se identifica a paisagem rural como área onde se estabelecem as relações entre os aspectos naturais, sociais e econômicos, dando a ela características específicas. 
Como um dos conceitos fundamentais da ciência geográfica, a leitura da paisagem sob a ótica científica humana se faz importantíssima para uma melhor concepção desse termo, levando-se em consideração outras formas de interpretação e não somente aquela ligada aos aspectos físicos. Fez-se necessária essa análise da evolução histórica do conceito de paisagem para que se torne possível entender as perspectivas atuais que envolvem essa abordagem conceitual e compreender os acontecimentos na paisagem rural do rio Guabirioba.

\section{A Paisagem Rural do Rio Guabiroba (GUARAPUAVA-PR)}

Entender a paisagem rural é compreender tanto a dinâmica econômica, quanto a dos indivíduos. Desse modo, se apresentará aqui algumas interpretações da realidade socioeconômica dos pequenos produtores da paisagem rural do Guabiroba, localizada na área rural do município de Guarapuava (ver Mapa 1). Essa realidade pôde ser observada e interpretada com base nos procedimentos metodológicos citados na introdução deste texto (trabalhos de campo, entrevistas e produção de imagens).

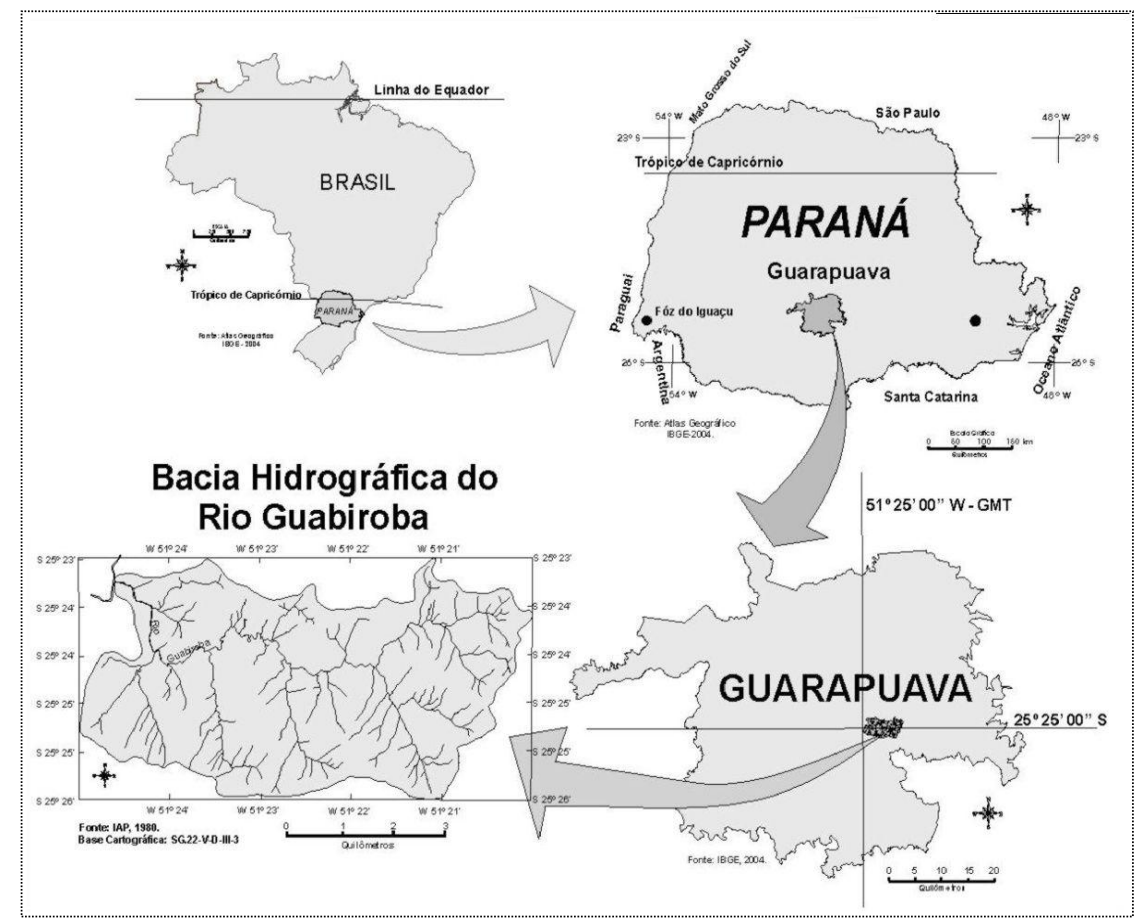

Mapa 1: Localização geográfica da área de estudo - Bacia Hidrográfica do Rio Guabiroba. Fonte: LUIZ, 2008, p. 65. 
Informações organizadas por Luiz (2007) apontam que a área total é aproximadamente de $23,7 \mathrm{~km}^{2}$ e que, atualmente, são cerca de 150 proprietários de terra que vivem nesta paisagem. A imagem a seguir (Figura 1) apresenta a estrada de acesso à paisagem rural. Esta entrada é um dos principais limites entre a zona urbana (Bairro Santana) e a zona rural.

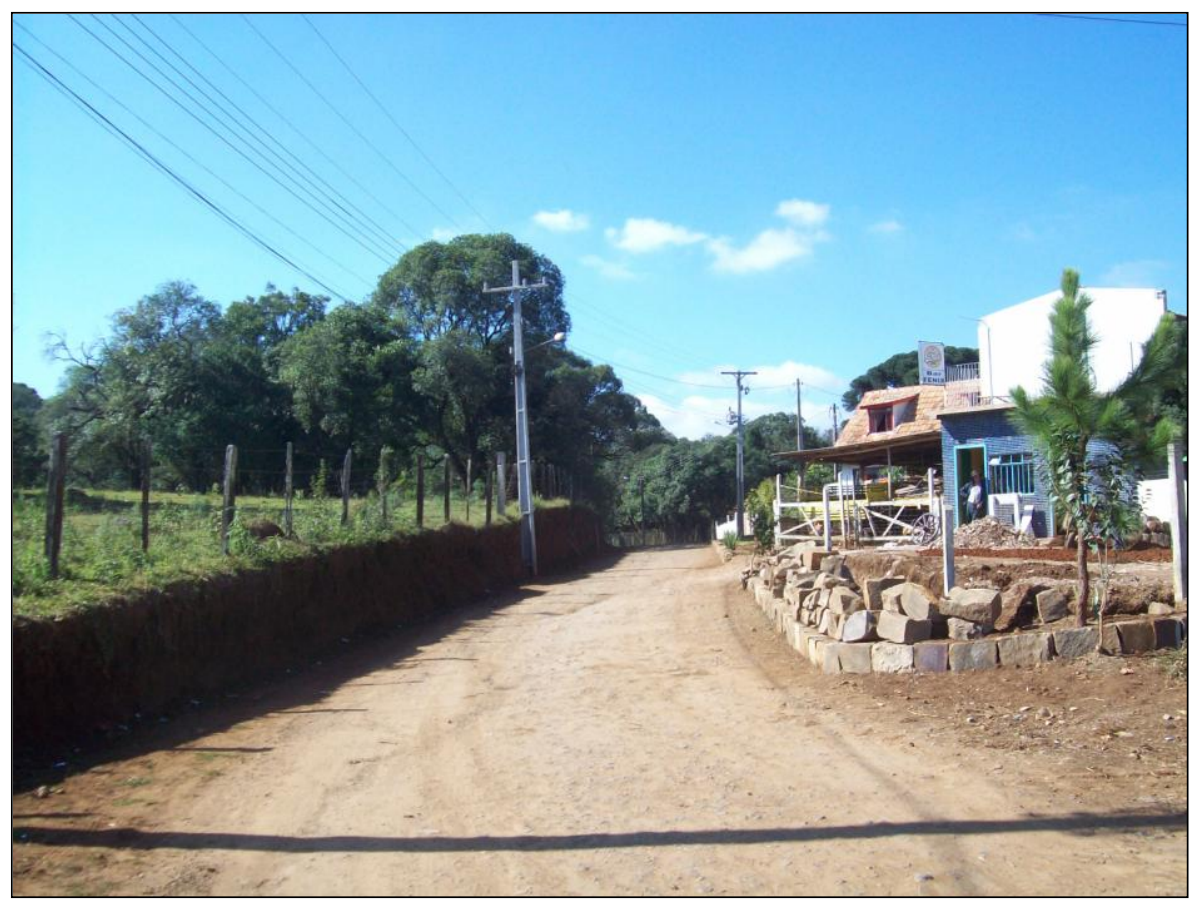

Figura1: Estrada de acesso à paisagem rural do Guabiroba - Limite entre zona urbana e rural. Autor: VERONEZZI, 2010.

Por meio de dados também apresentados por Luiz (2007) é possível entender que a paisagem atual é resultado de diversos processos históricos de transformação que ocorreram ao longo dos anos e que atingiram de forma potencial os pequenos agricultores inseridos nesta paisagem rural.

Observa-se na área de estudo que o homem vem buscando a interação com a natureza a fim de que ela lhe proporcione recursos financeiros, uma vez que "(...) os diversos usos se interagem e condicionam as mudanças na paisagem, proporcionadas pelos fenômenos físicos naturais e também pelo estabelecimento de pequenos agricultores (...)" (LUIZ, p. 117), que "produzem" a paisagem conforme determinados interesses. As principais transformações ocorridas nessa paisagem foram motivadas principalmente pelos "ciclos econômicos que a região 
passou" (LUIZ, 2007, p. 123). Assim, a construção da paisagem rural do Guabiroba vem sendo motivada pelo avanço da utilização das terras com a finalidade da pastagem para a criação de gado, além do cultivo de diversas produções agrícolas, principalmente como forma de subsistência, a partir da prática da produção orgânica.

Nesse tipo de produção o pequeno proprietário ${ }^{4}$ tem por objetivo criar e cultivar animais e plantas com o intuito de sustentar a família e efetuar algumas trocas com vizinhos mais próximos por produtos que não possui, além da comercialização em feiras semanais na cidade de Guarapuava e outros municípios da região. No caso da paisagem em análise, milho, feijão, mandioca e soja são os principais gêneros produzidos pelos pequenos produtores. Por outro lado, a criação animal é caracterizada por suínos, caprinos, ovinos, bovinos e galináceos.

É possível observar na Figura 2 três realidades desta paisagem rural: áreas com mata preservada - no canto superior direito; áreas de reflorestamento - à esquerda; e áreas de pastagem de gado à direita, abaixo dos remanescentes florestais. Tem-se também nesta imagem algumas atividades econômicas que compõem a paisagem rural do Guabiroba.

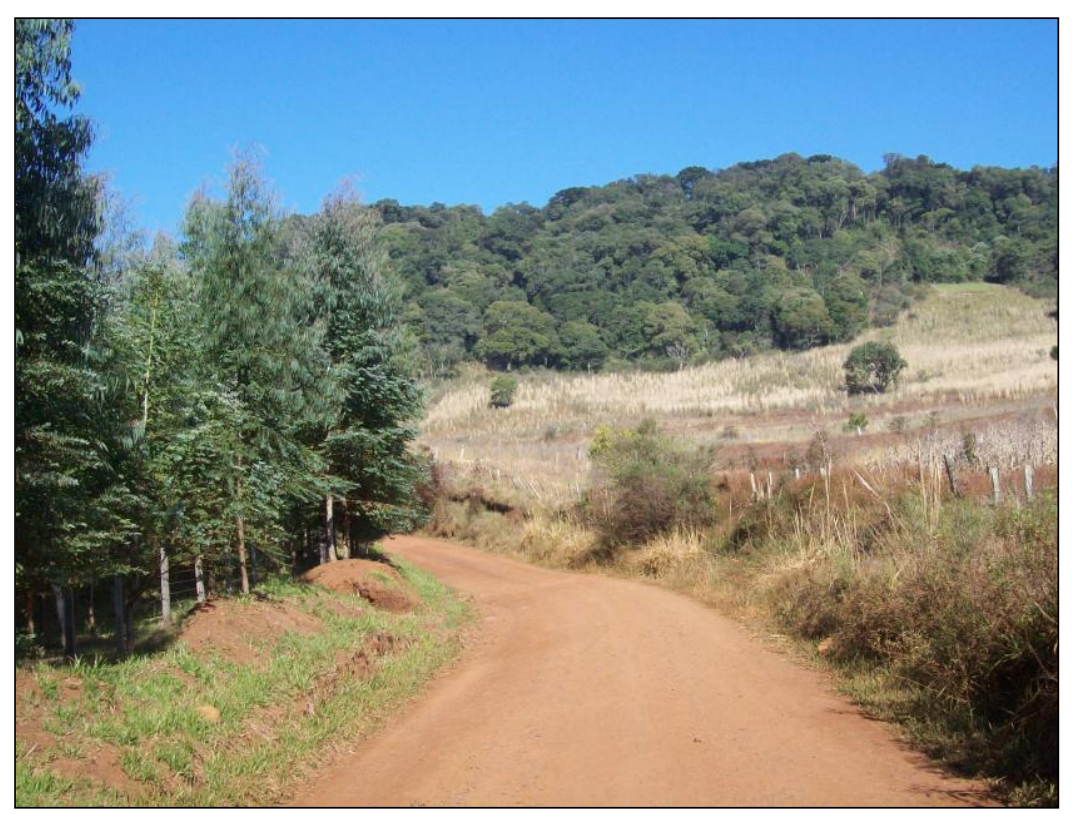

Figura 2: A paisagem construída (áreas de reflorestamento, pastagem e floresta). Fonte: VERONEZZI, maio, 2009.

\footnotetext{
${ }^{3}$ Para saber mais informações sobre os ciclos econômicos regionais, verificar: LUIZ, J. C. (2007) As unidades de paisagem na Bacia do Rio Guabiroba - Guarapuava (PR) e a fragilidade ambiental. 200 f. Dissertação (Mestrado) - UEM, Maringá.

${ }^{4}$ Para o desenvolvimento desse estudo optou-se por entrevistar e conhecer as atividades desenvolvidas essencialmente pelos pequenos proprietários.
} 


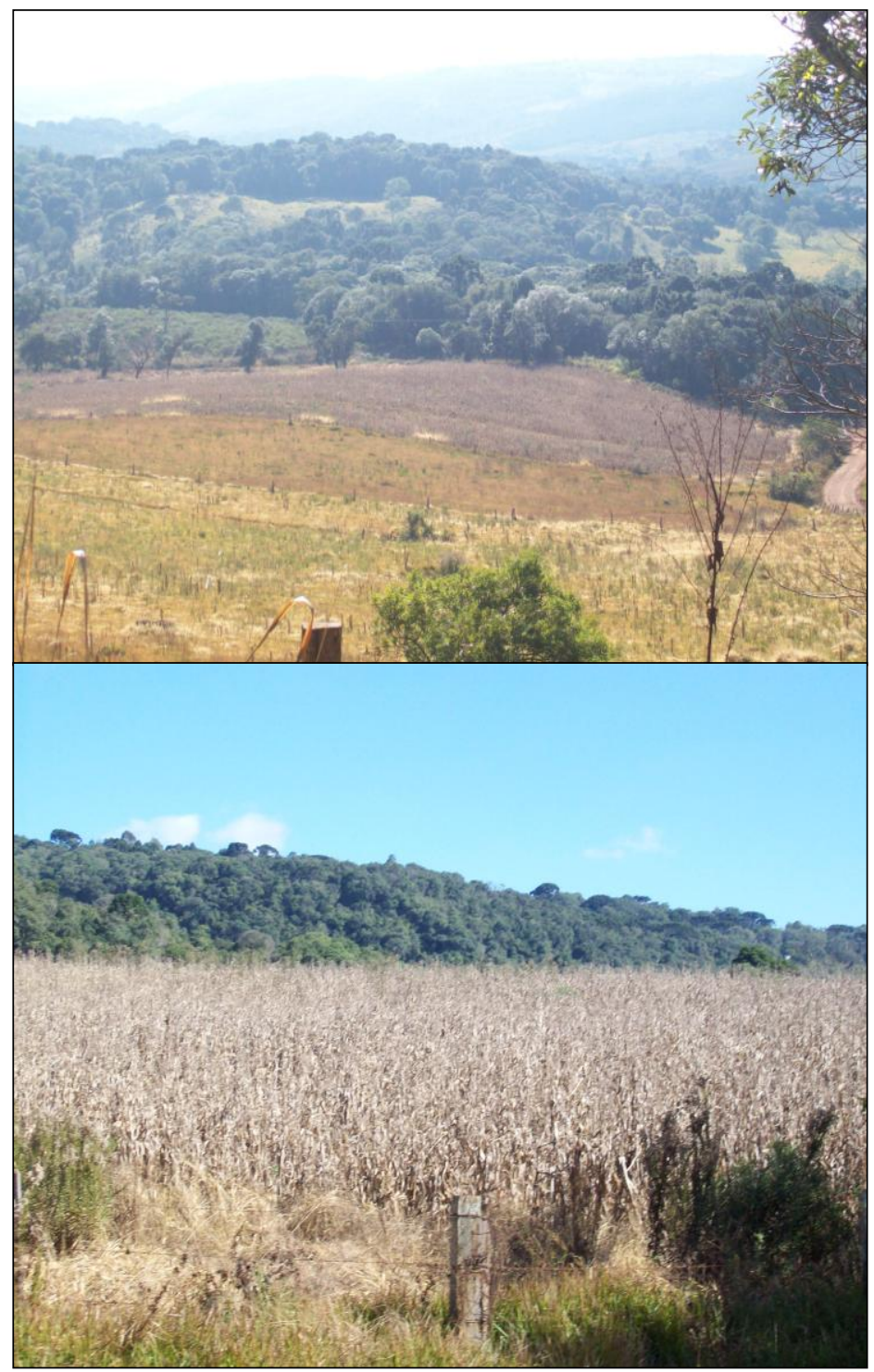

Figura 3: Contraste na paisagem rural do Guabiroba.

Fonte: VERONEZZI, maio, 2009.

Tendo como base essa imagem, pode-se observar que áreas de pastagem de gado e plantações agrícolas convivem com áreas de floresta. Nas zonas de maior altitude prevalecem os remanescentes de matas e nas áreas mais planas - de menor altitude - observam-se grandes clareiras de pastagem, construídas por ações humanas.

Nas imagens acima se pode observar que as atividades agropecuárias só não avançam mais na paisagem devido ao fato do terreno apresentar algumas 
características altimétricas, que são consideradas condições desfavoráveis para a progressão dessas práticas. A Figura 4 traz uma imagem que representa as diversas formas de utilização da terra na paisagem rural do Guabiroba, dando, desta maneira, subsídios para interpretar as atividades socioeconômicas que permitem a (re)construção da paisagem.

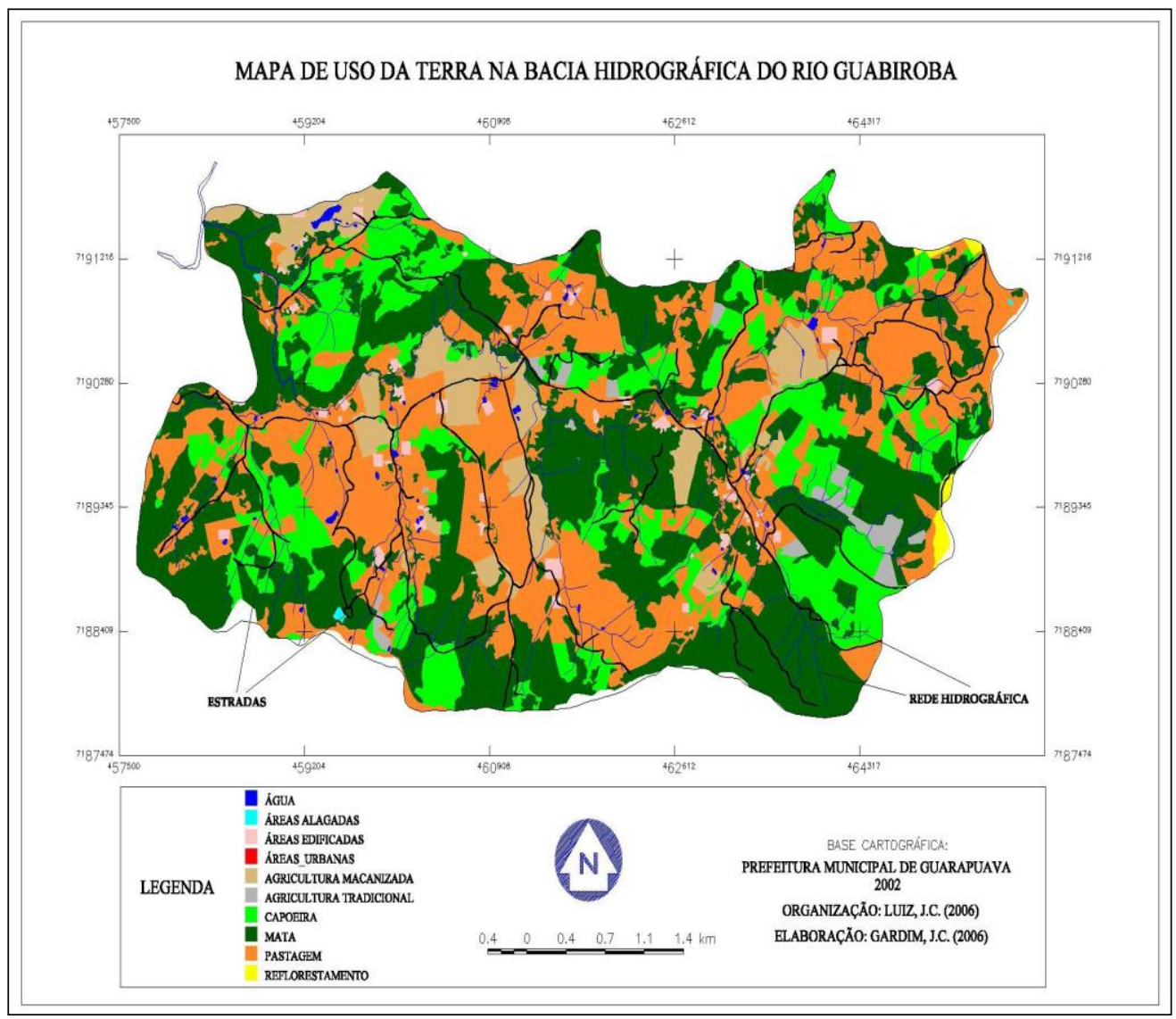

Figura 4: Uso da terra na paisagem rural do Rio Guabiroba.

Fonte: LUIZ, 2008.

O Quadro 1 indica as várias formas de utilização da terra no Guabiroba. Pode-se perceber que várias são as atividades humanas que permitem a transformação dessa paisagem rural. A agricultura mecanizada e tradicional, a pecuária, as áreas de pastagem, reflorestamento e áreas edificadas somam $48,71 \%$ do total das atividades socioeconômicas desenvolvidas nessa paisagem. 


\begin{tabular}{|c|c|}
\hline Formas de uso da terra & Total de classes $(\%)$ \\
\hline Matas & 35,96 \\
\hline Pastagem & 30,49 \\
\hline Capoeira & 11,37 \\
\hline Agricultura tradicional & 7,23 \\
\hline Agricultura mecanizada & 6,05 \\
\hline Reflorestamento & 3,71 \\
\hline Campo & 2,58 \\
\hline Áreas alagadas & 1,34 \\
\hline Áreas edificadas & 1,23 \\
\hline Total & 100 \\
\hline
\end{tabular}

Quadro 1: Formas de utilização da terra no Guabiroba. Fonte: LUIZ, 2008.

Organização: Dados adaptados por VERONEZZI, 2009.

A paisagem rural do Guabiroba vem passando por várias transformações ao longo do tempo. Modificações que vão dando uma nova configuração à paisagem construída, tornando-a, portanto, única e singular. Milton Santos (1997, p. 66) já relatava que "uma paisagem é uma escrita sobre a outra, é um conjunto de objetos que têm idades diferentes, é uma herança de diferentes momentos (...)" e que, desta forma, pode ser considerada como uma categoria que está em constante construção.

É nesse contexto que se destaca a prática da agricultura orgânica, entendida aqui como um modo de produção que promove a construção dessa paisagem rural por meio da potencialização da produção agropecuária de forma socialmente justa e em equilíbrio com a natureza (a partir de um enfoque ambiental, econômico, social e cultural) e que congrega os elementos que permitem a interpretação da paisagem rural.

A responsabilidade ambiental dos pequenos produtores rurais da região do rio Guabiroba foi percebida por meio do discurso dos entrevistados. Ficava claro durante as entrevistas e nas observações efetuadas que, de modo geral, eles praticam suas atividades agropecuárias de uma forma a não agredir o ambiente natural (sem a utilização de agrotóxicos), plantando produtos orgânicos para seu sustento e tratando os animais com o resto da alimentação da família e com artigos 
produzidos na propriedade.

Em um dos relatos um pequeno produtor morador dessa paisagem narra como se desenvolve a produção orgânica em sua propriedade. O agricultor afirma que em seu sítio - com cerca de 15 alqueires - onde metade da área é de reserva de proteção ambiental, a produção de alimentos é bastante variada e o cultivo se mantém há cerca de 17 anos sem a utilização de agrotóxicos. Na mesma entrevista ele conta que os lucros que obtém com a produção são divididos entre todos os membros da família. A produção que predomina na propriedade é a de mandioca. Ela, além de servir para consumo próprio, é a base de comercialização que permite o sustento da família do agricultor.

Em relação à prática da agricultura orgânica, Hamerschimidt (2006) revela que os produtores economizam cerca de 10 a $15 \%$ menos que os produtores convencionais (que utilizam agrotóxicos). Ele afirma também que no início da mudança da agricultura convencional para a orgânica a produção é menor. Porém, após esta fase, quando o solo já está equilibrado biologicamente, a produção pode ser igual ou até aumentar quando comparada à forma convencional de produção - o que acontece com o agricultor mencionado aqui.

Outro entrevistado enfatiza que, se praticar a agricultura orgânica de maneira correta, ela é bastante lucrativa e traz inúmeros benefícios econômicos, sociais e ambientais - além de estimular o trabalho da família no próprio sitio e permitir uma maior fixação dos sujeitos nessa paisagem. Os agricultores fontes de informação ainda revelam, de modo geral, a independência e flexibilidade que possuem para comercializar os produtos que por eles são cultivados. A maior parte deles vende o excedente em feiras ou para supermercados, não ficando "amarrados" (termo constante na fala de vários entrevistados) exclusivamente a um determinado atravessador.

Um número considerável de entrevistados indicou que a produção de alimentos orgânicos teve como início a união de alguns pequenos produtores da região de Guarapuava que, insatisfeitos com o sistema convencional de produção, buscaram técnicas alternativas. Segundo eles, a Fundação Rureco ${ }^{5}$ teve um papel importante na construção de tal prática

Vários são os elementos/atividades que fomentam a construção da paisagem

\footnotetext{
${ }^{5}$ A fundação RURECO é uma ONG (Organização Não Governamental) que tem como objetivo apoiar e articular regionalmente as ações das organizações dos pequenos agricultores nas áreas de produção, beneficiamento, comercialização e do associativismo. Suas ações se orientam pelo estímulo à organização e à capacitação dos agricultores familiares pela difusão e busca de alternativas tecnológicas para produção e comercialização agrícolas, visando promover a independência, a autonomia e a autogestão do agricultor familiar, das suas organizações e das suas comunidades. A entidade nasceu da insatisfação dos agricultores familiares frente ao modelo de desenvolvimento agrícola adotado no Brasil na década de 1960, modelo este que não respeitava o meio ambiente e nem as pessoas, forçou a saída dos agricultores familiares de suas propriedades provocando, ainda, a degradação dos recursos naturais (RURECO, 2010).
} 
rural do Guabiroba; dos quais, evidenciou-se neste texto de maneira breve, o papel dos pequenos produtores à luz da agricultura orgânica enquanto prática que permite significar tal paisagem, já que esta é considerada como um modo de produção que envolve os fatores necessários para a compreensão/interpretação da paisagem rural aqui apresentada.

\section{Considerações Finais}

Para a ciência geográfica a paisagem é um dos conceitos fundamentais e está presente em vários debates. A discussão acerca do termo paisagem sob a perspectiva humanista e as atividades potencializadoras da construção/produção das paisagens rurais são de grande valor para a sistematização dos conhecimentos que envolvem a temática.

Com a finalidade de compreender a paisagem rural do rio Guabiroba, foi necessário fazer uma discussão acerca da amplitude conceitual que envolve o termo paisagem. As possibilidades de interpretação são as mais variadas possíveis permitindo diversas percepções. Nesse contexto, as paisagens e, no caso específico, a paisagem rural do Guabiroba, apresentam características particulares e mostram as várias relações econômicas, culturais e sociais materializadas por este termo.

Conforme trabalhado no decorrer deste artigo, o conceito de paisagem rural foi utilizado como uma possibilidade de interpretação/compreensão da realidade estudada, onde se observou que o mesmo é engendrado a partir de um dinâmico processo entre relações naturais, sociais, culturais e econômicas. Por meio da perspectiva da agricultura orgânica - modo de produção que envolve os princípios citados - a leitura da paisagem rural pode ser efetuada e oportuniza novas reflexões acerca do tema.

\section{Bibliografia}

BERQUE, Augustin. (2004) Paisagem-marca, paisagem-matriz: elementos da problemática para uma geografia cultural. In: CORRÊA, Roberto L.; ROSENDAHL, Zeny. (org.). Paisagem, tempo e cultura. $2^{\text {a }}$ edição. Rio de Janeiro: Editora da UERJ. pp. 84-91.

BERTRAND, Georges. (2004) Paisagem e geografia física global. Esboço metodológico. RA'EGA. Curitiba, $\mathrm{n}^{\circ}$ 8. pp. 141-152.

CAPEL, Horacio. (1981) Filosofia y Ciência en la Geografía Contemporânea. Barcelona: Barcanova.

CAVACO, Carminda. (2005) As Paisagens Rurais: do "Determinismo Natural" ao "Determinismo Político?’.Finisterra XL, vol. 79. pp. 73-101. 
CHRISTOFOLETTI, Antonio. (1999) Modelagem de sistemas ambientais. São Paulo: Edgard Blucher.

CORRÊA, Roberto L.; ROSENDAHL, Zeny. (org.). (2004) Paisagem, tempo e cultura. $2^{\text {a }}$ edição Rio de Janeiro: Editora da UERJ.

COSGROVE, Denis. (2004) A Geografia está em toda parte: cultura e simbolismo nas paisagens humanas. In: CORRÊA, Roberto L.; ROSENDAHL, Zeny. (Org.). Paisagem, tempo e cultura. $2^{\mathrm{a}}$ edição. Rio de Janeiro: Editora da UERJ. pp. 92123.

FAJARDO, Sergio. (2005) Paisagem rural e território econômico: possibilidades de leitura do espaço geográfico. In: ANAIS - XIV SEMANA DE GEOGRAFIA. Geografia e cinema: Poder, territorialidade e movimentos sociais. Departamento de Geografia da Universidade Estadual do Centro-Oeste. Guarapuava. UNICENTRO. pp. 31-39.

. (2008) Territorialidades corporativas no rural paranaense. Guarapuava: Ed. UNICENTRO.

FUNDAÇÃO RURECO. Institucional-História. Disponível: http://www.rureco.org.br/instituicao/institucional.htm. Acesso em: 15 abr. 2010. HAMERSCHIMIDT, Iniberto. (2006) Panorama da Agricultura Orgânica no Paraná. Curitiba, EMATER/PR. Disponível em: http://www.planetaorganico.com.br/trab_iniberto06.htm. Acesso em: 20 ago. 2010. LISBOA, Severina S. (2007) A importância dos conceitos da Geografia para a aprendizagem de conteúdos geográficos escolares. Revista Ponto de Vista, vol. 4. pp. 23-35.

LUIZ, José C. (2008) As unidades de paisagem na bacia do rio GuabirobaGuarapuava - PR - e a fragilidade ambiental. Estudos Geográficos, Rio Claro, 6 (1). pp. 63-88.

. (2007) As unidades de paisagem na Bacia do Rio Guabiroba Guarapuava $(P R)$ e a fragilidade ambiental. 200 f. Dissertação (Mestrado em Geografia), Universidade Estadual de Maringá, Maringá.

MAXIMIANO, Liz A. (2004) Considerações sobre o conceito de paisagem. $R A^{\prime} E G A$. Curitiba, UFPR, $\mathrm{n}^{\circ}$ 8. pp. 83-91.

MENDONÇA, Francisco. (2001) Geografia Física: Ciência Humana? 7ª ed. São Paulo: Contexto.

PASSOS, Messias M. (1998) Por uma história ecológica da paisagem. Geografia em atos, $\mathrm{n}^{\circ} 1$, v. 1 . pp. 87-109.

RIBAS VILAS, Jordi. (1992) Planificación y gestión del paisaje rural. In: BOLÓS, Maria de. Manual de ciência del paisaje: teoria, método y aplicaciones. Madrid: Masson. pp. 250-262.

RISSO, Luciene C. (2008) Paisagens e cultura: uma reflexão teórica a partir do estudo de uma comunidade indígena amazônica. Espaço e cultura, Rio de Janeiro, $n^{\text {o } 23 . ~ p p . ~ 67-76 . ~}$ 
SALGUEIRO, Teresa B. (2001) Paisagem e Geografia. Finisterra. Lisboa. pp. 3753.

SANTOS, Milton. (1997) Metamorfoses do espaço habitado. $5^{\text {a }}$ ed. São Paulo: HUCITEC.

(2002) A natureza do espaço: técnica e tempo - razão e emoção. São Paulo: Edusp.

SCHIER, Raul A. (2003) Trajetórias do conceito de paisagem na geografia. $R A^{\prime} E G A$, Curitiba, no 7 . pp. 79-85.

Data de submissão: 24/03/2015.

Data de aceite: 28/07/2015. 